\title{
Effects of 17 $\beta$-estradiol and 2-methoxyestradiol on the oxidative stress-hypoxia inducible factor-1 pathway in hypoxic pulmonary hypertensive rats
}

\author{
LI WANG, QUAN ZHENG, YADONG YUAN, YANPENG LI and XIAOWEI GONG
}

Department of Respiratory Disease and Critical Care Medicine, The Second Hospital of Hebei Medical University, Shijiazhuang, Hebei 050000, P.R. China

Received December 2, 2015; Accepted November 25, 2016

DOI: $10.3892 /$ etm.2017.4243

\begin{abstract}
The present study aimed to investigate the effects of $17 \beta$-estradiol (E2) and 2-methoxyestradiol (2ME) on the oxidative stress-hypoxia inducible factor-1 (OS-HIF-1) pathway in hypoxic pulmonary hypertensive rats. Female Sprague-Dawley rats were divided randomly into 4 groups, as follows: i) Control (Group A); ii) ovariectomy (OVX) + hypoxia (Group B); iii) OVX + hypoxia + E2 injection (Group C); and iv) $2 \mathrm{ME}$ injection (Group D). The rats were maintained under hypoxic conditions for 8 weeks, and mean pulmonary artery pressure (mPAP) and pulmonary arteriole morphology were measured. The reactive oxygen species, superoxide dismutase (SOD), manganese superoxide dismutase (MnSOD), and copper-zinc superoxide dismutase (Cu/ZnSOD) levels in serum were also measured. MnSOD and HIF-1 $\alpha$ expression levels in lung tissue were determined by western blotting and reverse transcription-quantitative polymerase chain reaction. The mPAP and arterial remodeling index were significantly elevated following chronic hypoxia exposure; however, experimental data revealed a reduced response in E2 and 2ME intervention rats. Compared with Group A, Group B had significantly elevated oxidative stress levels, as illustrated by increased serum ROS levels, decreased serum SOD and MnSOD levels and decreased MnSOD mRNA and protein expression levels in lung tissue. Furthermore, HIF- $1 \alpha$ mRNA and protein expression in Group B was significantly elevated compared with Group A. E2 and 2ME intervention significantly attenuated the aforementioned parameter changes, suggesting that E2 and 2ME partially ameliorate hypoxic pulmonary hypertension. The underlying mechanism of this may be associated with the increase in MnSOD activity and
\end{abstract}

Correspondence to: Dr Yadong Yuan, Department of Respiratory Disease and Critical Care Medicine, The Second Hospital of Hebei Medical University, 215 Heping West Road, Shijiazhuang, Hebei 050000, P.R. China

E-mail: yadongyuandoc@126.com

Key words: pulmonary hypertension, hypoxia, 17 $\beta$-estradiol, 2-methoxyestradiol, oxidative stress, hypoxia inducible factor- $1 \alpha$, rat expression and reduction in ROS level, which reduces the levels of transcription and translation of HIF-1 $\alpha$.

\section{Introduction}

Current epidemiologic data suggests that the global prevalence of pulmonary hypertension ( $\mathrm{PH})$ is $1 \%$, and this increases to $10 \%$ in individuals $>65$ years old (1). $\mathrm{PH}$ is characterized by elevated pulmonary vascular resistance, progressive right ventricle (RV) hypertrophy and, ultimately, RV failure, which is key in the development of chronic pulmonary heart disease (2). The development of PH is largely due to hypoxia caused by chronic obstructive pulmonary disease (3); therefore, inhibiting the development of chronic hypoxia-induced $\mathrm{PH}(\mathrm{HPH})$ may effectively prevent the occurrence of many cardiovascular diseases. Hypoxia may cause disease by increasing the level of intracellular reactive oxygen species (ROS) (4). Relatedly, redox signaling has been suggested to be involved in the regulation of hypoxic pulmonary vasoconstriction under acute hypoxia, and in cell proliferation during chronic hypoxia $(5,6)$, the underlying mechanisms remain unknown. ROS, acting as signaling molecules, modulate diverse physiological processes including the regulation of growth factor signaling, the hypoxic response, inflammation and the immune response in mammalian cells $(7,8)$. Hypoxia-inducible factor-1 (HIF-1), a master regulator of gene expression induced by hypoxia, serves an important role in the origin and development of HPH (9). A recent study has demonstrated that ROS serve an important role in the regulation of HIF-1 expression and activity (10).

Although emerging evidence demonstrates the protective effect of estrogen and its metabolites on pulmonary arterial hypertension $(11,12)$, it remains unclear whether this occurs via adjustments of the oxidative stress-hypoxia inducible factor- $1 \alpha$ (OS-HIF-1 $\alpha$ ) pathway. Previous research by the current authors indicated that the mean pulmonary artery pressure (mPAP) of ovariectomized (OVX) rats increased significantly under hypoxic conditions and that $17 \beta$-estradiol (E2) and 2-methoxy estradiol (2ME) partially reversed HPH development (13). In the current study, an HPH animal model was established, using OVX rats. Alterations to ROS, superoxide dismutase (SOD), manganese superoxide dismutase (MnSOD), copper-zinc superoxide dismutase $(\mathrm{Cu} / \mathrm{ZnSOD})$ and $\mathrm{HIF}-1 \alpha$ were examined 
in vivo to determine the effects of $\mathrm{E} 2$ and $2 \mathrm{ME}$ treatment on the OS-HIF-1 $\alpha$ pathway in this model.

\section{Materials and methods}

Animals and experimental design. A total of 32 healthy 6-8 week-old female Sprague-Dawley rats (weight, 170-190 g) were purchased from the Animal Center of the Hebei Medical University (Shijiazhuang, China). In accordance with previous modeling approaches (10), the rats were randomly divided into 4 groups ( $=8$ per group), as follows: i) Control (group A); ii) $\mathrm{OVX}+$ hypoxia (group B); iii) $\mathrm{OVX}+$ hypoxia + E2 (group C); and iv) OVX + hypoxia $+2 \mathrm{ME}$ groups (group D). In groups $\mathrm{B}, \mathrm{C}$ and $\mathrm{D}$ rats were anesthetized with pentobarbital sodium $(40 \mathrm{mg} / \mathrm{kg}$, intraperitoneal; Shanghai Haling Biotechnology Co., Ltd., Shanghai, China), the abdominal cavity was subsequently opened and the bilateral ovaries were removed. In group A, rats were anesthetized with pentobarbital sodium $(40 \mathrm{mg} / \mathrm{kg}$, intraperitoneal; Shanghai Haling Biotechnology Co., Ltd.), the abdominal cavity was opened and the ovaries were located but not removed. Following the operation, the rats in groups $\mathrm{A}$ and $\mathrm{B}$ received subcutaneous injection of physiological saline $(0.1 \mathrm{ml} /$ day for 8 weeks), group C received a subcutaneous injection of E2 (20 $\mu \mathrm{g} / \mathrm{kg}$ /day for 8 weeks; Sigma-Aldrich; Merck Millipore, Darmstadt, Germany) and group D received a subcutaneous injection of 2ME (240 $\mu \mathrm{g} / \mathrm{kg} /$ day for 8 weeks; Sigma-Aldrich; Merck Millipore). Exposure to hypoxic conditions and E2, $2 \mathrm{ME}$ or physiological saline was initiated simultaneously 1 week after surgery. To provide hypoxic conditions, rats were maintained in a normobaric chamber (CJ-DO2245; Changjin Science Co., Ltd., Changsha, China) with a controlled $\mathrm{O}_{2}$ concentration of $10.0 \pm 0.5 \%$. Soda lime and anhydrous calcium chloride were used to absorb excess carbon dioxide and water vapor, maintaining the carbon dioxide concentration at $<0.5 \%$. The rats of group A were housed in normal air. All rats were housed in a temperature-controlled environment $\left(25^{\circ} \mathrm{C}\right)$ with a $12 \mathrm{~h}$ light-dark cycle, fed a standard laboratory diet and provided with water ad libitum. Bedding was changed once a week. The rats were maintained under air/hypoxic conditions for 8 weeks in order to establish a hypoxic PH model. The present study was performed in strict accordance with the recommendations in the Guide for the Care and Use of Laboratory Animals of the National Institutes of Health. The animal use protocol was reviewed and approved by the Institutional Animal Care and Use Committee of Hebei Medical University.

Measurement of mPAP and pulmonary arteriole morphology. Measurement of mPAP was performed as described previously (14). Briefly, after 8 weeks, the rats were anesthetized by an intraperitoneal injection of pentobarbital sodium $(40 \mathrm{mg} / \mathrm{kg}$; Shanghai Haling Biotechnology Co., Ltd.). A longitudinal skin incision was made on the right side of the neck, and blunt layer-by-layer separation of the tissues was performed until the right external jugular vein was exposed. A polyethylene catheter was gradually inserted into the pulmonary artery through an incision in the right external jugular vein, and the mPAP was recorded using a pressure transducer, which was interfaced to a BL-420S Bio Lab System (Chengdu TME Technology Co., Ltd., Chengdu, China). Following measurement of mPAP, blood samples ( $2.0 \mathrm{ml}$ per rat) were drawn from the pulmonary artery of the rats. These were centrifuged for $10 \mathrm{~min}$ at 3,000 $\mathrm{x} g$ and the supernatant was collected and stored at $-80^{\circ} \mathrm{C}$ until use. The rats were then sacrificed by exsanguination and the lungs were isolated and washed with physiological saline repeatedly. Three lobes of the right lung were surgically removed, immediately snap frozen in liquid nitrogen and stored at $-80^{\circ} \mathrm{C}$ until use. The upper lobe of the left lung was removed and fixed in a $10 \%$ formalin solution overnight, which was followed by paraffin embedding. Subsequently, lung sections $(4-\mu \mathrm{m})$ were prepared and stained with hematoxylin and eosin. Sections were examined under a light microscope (Eclipse 55i; Nikon Corporation, Tokyo, Japan) for pulmonary arteriolar morphological analysis.

Assessment of pulmonary arteriolar ultrastructural changes. To assess the pulmonary arteriolar ultrastructure, lung tissue was fixed in $4 \%$ glutaraldehyde, and postfixed in $1 \% \mathrm{OsO}_{4}$. Ultrathin sections were cut on a microtome, placed on copper grids, stained with uranyl acetate and lead citrate, and examined with a transmission electron microscope.

Determination of ROS, SOD, MnSOD, and Cu/ZnSOD. Serum ROS levels were measured using the Fenton reaction and Griess color rendering principle according to the ROS detection kit instructions (cat. no. A018; Jiancheng Bioengineering Institute, Nanjing, China).

SOD, $\mathrm{Cu} / \mathrm{ZnSOD}$, and MnSOD levels in serum were determined using the xanthine oxidase method according to the instructions in the SOD activity detection kit (cat. no. A001; Jiancheng Bioengineering Institute).

Reverse transcription-quantitative polymerase chain reaction $(R T-q P C R)$. RT-qPCR was used to detect the expression of MnSOD and HIF-1 $\alpha$ mRNA, as follows: Total RNA was extracted from lung tissue using TRIzol (Takara Biotechnology Co., Ltd., Dalian, China) and $2 \mu \mathrm{g}$ of each RNA sample was reverse transcribed to cDNA. The RNA concentration and purity were determined using an ultraviolet spectrophotometer (756MC; Shanghai Precision \& Scientific Instrument Co., Ltd., Shanghai, China). RT was performed as follows: $2 \mu \mathrm{g}$ of total RNA was added into an RT reaction system tube containing $10 \mu \mathrm{l}$ avian myeloblastosis virus (AMV) buffer, $5 \mu 1 \mathrm{dNTPs}, 2.5 \mu \mathrm{l}$ oligo(dT) primer, $2.5 \mu \mathrm{l} \mathrm{AMV}$ and 2.5 $\mu \mathrm{l}$ RNase inhibitor (cat. no. 2313A; all Takara Biotechnology Co., Ltd.). Diethyl pyrocarbonate (DEPC) solution was added to make up $50 \mu \mathrm{l}$ total reaction volume. After mixing and centrifuging at $4^{\circ} \mathrm{C}$ and $256 \mathrm{x} g$ for $5 \mathrm{sec}$, the reaction system was subjected to RT. The conditions for RT were as follows: $42^{\circ} \mathrm{C}$ for $30 \mathrm{~min}, 99^{\circ} \mathrm{C}$ for 5 min and $5^{\circ} \mathrm{C}$ for $5 \mathrm{~min}$. The following specific oligonucleotide primers were used: Forward, 5'-GCCTCAGCAATGTTGTGTCG-3'; and reverse, 5'-TGATTAGAGCAGGCGGCAAT-3' for MnSOD; and forward, 5'-CTCAGAGGAAGCGAAAAATGG-3'; and reverse, 5'-AATTCTTCACCCTGCAGTAGG-3' for HIF-1 $\alpha$ (Sangon Biotech Co., Ltd., Shanghai, China). GAPDH (Forward, 5'-CACCTTTGATGCTGGGGCTG-3'; and reverse, 5'-TGG TATTCGAGAGAAGGGAGGG-3'; Sangon Biotech Co., Ltd.) was used as an internal reference to normalize the mRNA expression levels of MnSOD and HIF-1 $\alpha$. The qPCR reaction system contained $5 \mu 1$ 10xTaq buffer, $3 \mu 1 \mathrm{MgCl}_{2}(25 \mathrm{mmol} / \mathrm{l})$, $0.5 \mu \mathrm{ldNTP}(10 \mathrm{mmol} / \mathrm{l}), 1 \mu \mathrm{l}$ forward primer $(10 \mu \mathrm{mol} / \mathrm{l}), 1 \mu \mathrm{l}$ 
A

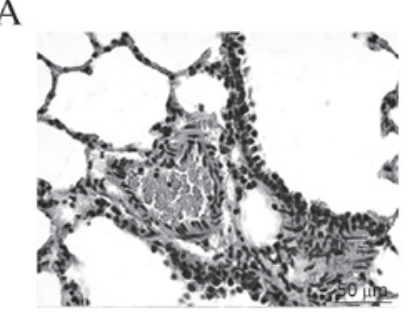

C

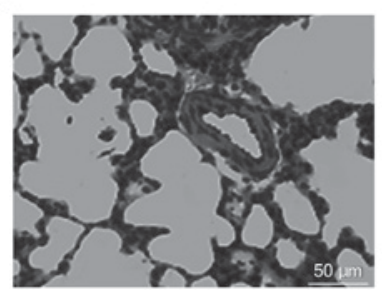

$\mathrm{B}$

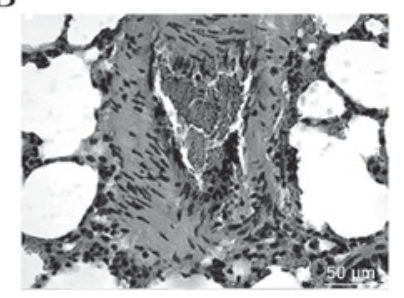

$\mathrm{D}$

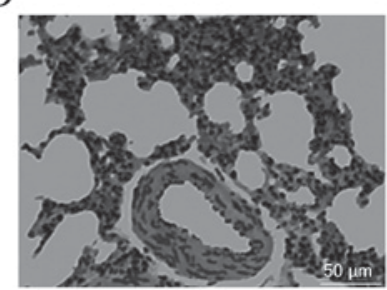

Figure 1. Effect of E2 and 2ME on pulmonary arteriole morphological changes in rats, illustrated by hematoxylin and eosin staining. Scale bar, $50 \mu \mathrm{m}$. (A) Control group; (B) OVX + hypoxia group; (C) OVX + hypoxia + E2 group; (D) OVX + hypoxia + 2ME group. OVX, ovariectomized; E2, estradiol; ME, methoxyestradiol.

reverse primer (10 $\mu \mathrm{mol} / \mathrm{l}), 2.5 \mu \mathrm{l}$ cDNA, $0.5 \mu \mathrm{l}$ Taq DNA polymerase and DEPC solution to give a total reaction volume of $50 \mu \mathrm{l}$ (all Takara Biotechnology Co., Ltd.). The conditions for qPCR were as follows: Initial denaturation at $94^{\circ} \mathrm{C}$ for $3 \mathrm{~min}$; 30 cycles of denaturation at $94^{\circ} \mathrm{C}$ for $40 \mathrm{sec}$, annealing at $54^{\circ} \mathrm{C}$ for $30 \mathrm{sec}$, and extension at $72^{\circ} \mathrm{C}$ for $1 \mathrm{~min}$; final extension at $72^{\circ} \mathrm{C}$ for $10 \mathrm{~min}$. Afterwards, $6 \mu \mathrm{l}$ of PCR product was used to perform $1.5 \%$ agarose gel electrophoresis. The electrophoresis image was analyzed using Quantity One Analysis Software (version 4.6; Bio-Rad Laboratories, Inc., Hercules, CA, USA).

Western blotting. Western blot analysis was used to detect the expression of MnSOD and HIF-1 $\alpha$ protein. Total protein was extracted from lung tissue using radioimmunoprecipitation assay lysis buffer (BestBio, Shanghai, China), and the protein content was determined by the improved Lowry method (15). Equal amounts of protein $(60 \mu \mathrm{g} / \mathrm{lane})$ from each sample were separated by SDS-PAGE on a 15\% polyacrylamide gel, and were subsequently electrophoretically transferred to a nitrocellulose membrane. The membranes were blocked with a 5\% nonfat dry milk solution in TBS with $0.1 \%$ Tween-20 (TBS-T, $\mathrm{pH}$ 8.0) for $2 \mathrm{~h}$ at room temperature and incubated in primary antibody dissolved in the blocking solution at $4^{\circ} \mathrm{C}$ overnight. The MnSOD protein was detected using a rabbit anti-MnSOD monoclonal antibody (1:1,000; ab68155; Abcam, Cambridge, MA, USA) and HIF-1 $\alpha$ was detected using a mouse anti-HIF-1 $\alpha$ monoclonal antibody (1:1,000; NB100-123; Novus Biologicals LLC, Littleton, CO, USA); a mouse anti-GAPDH monoclonal antibody (1:1,000; ab9484; Abcam) was used to confirm equal loading. Following three washes for $5 \mathrm{~min}$ in TBS-T, the membranes were incubated with horseradish peroxidase-conjugated immunoglobulin g (1:1,000; MAB1799; R\&D Systems, Inc., Minneapolis, MN, USA) corresponding to the primary antibody in the blocking buffer for 2.5-3.0 $\mathrm{h}$ at room temperature. Following three washes, the proteins were detected using luminol detection reagent (Santa Cruz Biotechnology, Inc.) and developed on X-ray film.

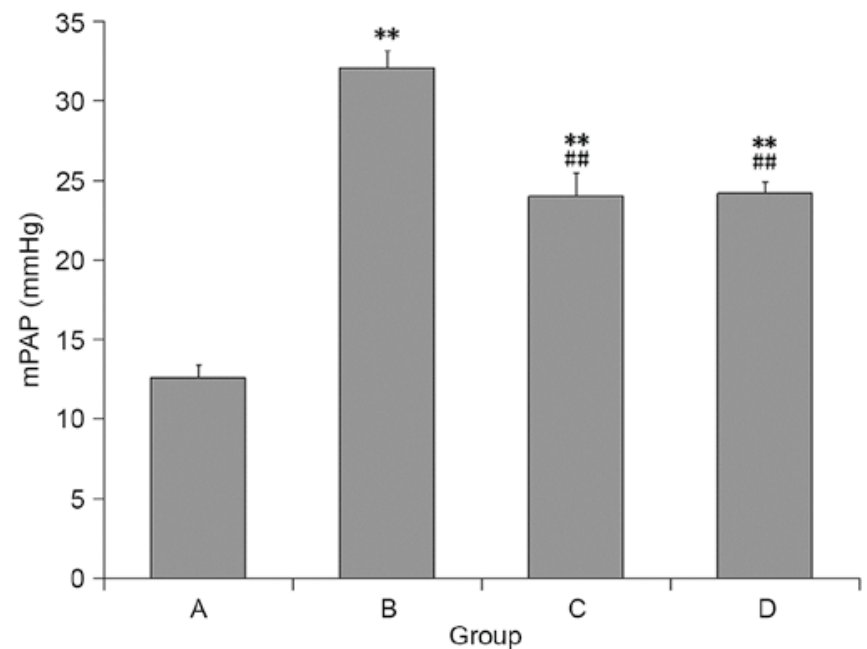

Figure 2. Effect of E2 and 2ME on pulmonary hypertension induced by chronic hypoxia in rats. (A) Control group; (B) OVX + hypoxia group; (C) OVX + hypoxia + E2 group; (D) OVX + hypoxia + 2ME group. ${ }^{* *} \mathrm{P}<0.01$ vs. $\mathrm{A} ;{ }^{\# \#} \mathrm{P}<0.01$ vs. $\mathrm{B}$. $\mathrm{n}=8$ rats in each group. OVX, ovariectomized; E2, estradiol; ME, methoxyestradiol; mPAP, mean pulmonary artery pressure.

Statistical analysis. All quantitative data are expressed as mean \pm standard deviation. Statistical analysis was performed using a one-way analysis of variance, followed by a least significant difference test for post hoc multiple comparisons. A $\mathrm{P}<0.05$ was considered to represent a statistically significant difference. Analyses were performed using SPSS 13.0 (SPSS, Inc., Chicago, IL, USA).

\section{Results}

The animal model of $\mathrm{PH}$. During the experiments, rats in the control group were active, gained weight gradually and their body fur was smooth and lustrous, whereas in hypoxic groups, the fur of the rats was less healthy, they took shorter breaths, their food intake was lower, their bodies were smaller and their activity decreased gradually. Following 8 weeks of hypoxia exposure, OVX rats exhibited pulmonary vascular structural remodeling and $\mathrm{PH}$ characteristics, including a visible pulmonary arterial wall and smooth muscle layer thickening, luminal stenosis (Fig. 1) and a significant increase in mPAP compared with the control rats (Fig. 2). However, the above changes were lessened in the rats treated with E2 and 2ME as compared with the OVX + hypoxia rats.

Ultrastructural changes of the pulmonary arteriole. Pulmonary arteriolar ultrastructural changes were observed via transmission electron microscopy. In the control group, the mitochondria were distributed evenly and arranged orderly, and their double membrane structure was clear without obvious swelling. In the OVX + hypoxia group, the mitochondria were reduced in number, swollen, and deformed with fractured cristae. These changes were less apparent the $\mathrm{E} 2$ and $2 \mathrm{ME}$ intervention groups than in the OVX + hypoxia group (Fig. 3).

Serum ROS levels. Compared with the control group, the serum ROS level of the OVX + hypoxia group was significantly higher $(\mathrm{P}<0.01)$. Additionally, compared with the OVX + hypoxia 


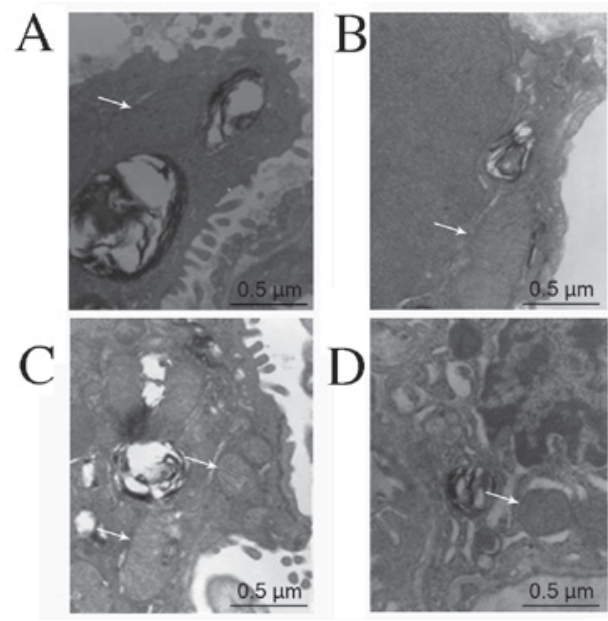

Figure 3. Transmission electron microscopic examination of pulmonary arteriole. Scale bar, $50 \mu \mathrm{m}$. (A) Control group; (B) OVX + hypoxia group; (C) OVX + hypoxia + E2 group; (D) OVX + hypoxia + 2ME group. OVX ovariectomized; E2, estradiol; ME, methoxyestradiol.

group, the serum ROS levels in E2 and 2ME intervention groups decreased significantly $(\mathrm{P}<0.01)$, and there was no significant difference between these two groups ( $\mathrm{P}>0.05$ ) (Fig. 4).

SOD, MnSOD, and Cu/ZnSOD levels. Compared with the control group, SOD and MnSOD levels in serum were significantly decreased $(\mathrm{P}<0.05$ or $\mathrm{P}<0.01)$. In addition, compared with the OVX + hypoxia group, levels of these enzymes were significantly higher $(\mathrm{P}<0.01)$ in the $\mathrm{E} 2$ and $2 \mathrm{ME}$ intervention groups. In the $\mathrm{E} 2$ intervention group, MnSOD was significantly increased compared with the $2 \mathrm{ME}$ group $(\mathrm{P}<0.01)$. There was no significant difference in $\mathrm{Cu} / \mathrm{ZnSOD}$ activity between the groups (P>0.05) (Fig. 4).

MnSOD mRNA and protein expression. Compared with the control group, MnSOD mRNA (Fig. 5) and protein expression (Fig. 6) in lung tissues of the other groups were significantly decreased $(\mathrm{P}<0.01)$. Compared with the OVX + hypoxia group, the expression of these in the $\mathrm{E} 2$ and $2 \mathrm{ME}$ intervention groups was significantly increased $(\mathrm{P}<0.01)$, and this increase was greater in the $2 \mathrm{ME}$ group.

HIF-1 $\alpha$ mRNA and protein expression. Compared with the control group, HIF-1 $\alpha$ mRNA (Fig. 5) and protein expression (Fig. 6) in lung tissues was significantly increased in all experimental groups $(\mathrm{P}<0.01)$. Compared with the OVX + hypoxia group, the HIF-1 $\alpha$ mRNA and protein levels in the E2 and 2ME intervention groups was significantly reduced $(\mathrm{P}<0.01)$. There was no significant difference between these two groups with regard to mRNA expression level ( $>>0.05$ ), but HIF-1 $\alpha$ protein expression was significantly lower in the $2 \mathrm{ME}$ group than the $\mathrm{E} 2$ group $(\mathrm{P}<0.01)$.

\section{Discussion}

HPH is characterized by pulmonary vasoconstriction and pulmonary vascular remodeling, of which the main pathological change is medial thickening, caused by enhanced proliferation of pulmonary artery smooth muscle cells $(16,17)$.

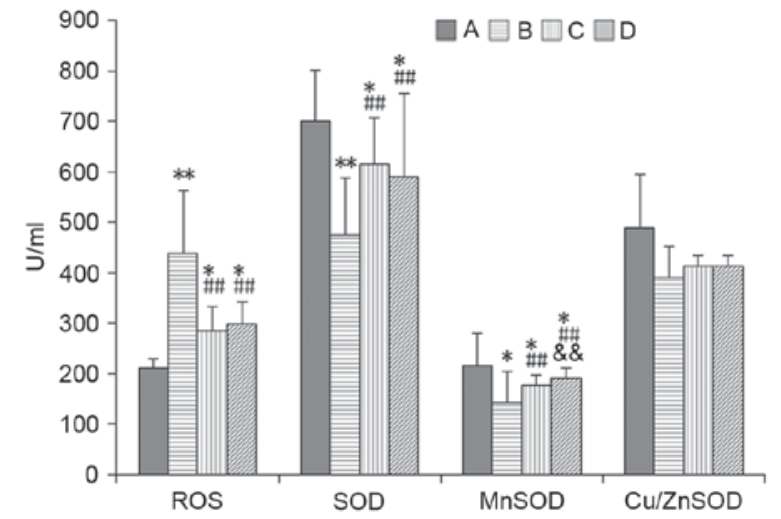

Figure 4. Comparison of the ROS, SOD, MnSOD, Cu/ZnSOD levels in serum among the groups. (A) Control group; (B) OVX + hypoxia group; (C) OVX + hypoxia + E2 group; (D) OVX + hypoxia + $2 \mathrm{ME}$ group. ${ }^{*} \mathrm{P}<0.05$; ${ }^{* *} \mathrm{P}<0.01$ vs. $\mathrm{A}$; ${ }^{\# \#} \mathrm{P}<0.01$ vs. $\mathrm{B}$; \&\& $\mathrm{P}<0.01$ vs. $\mathrm{C} . \mathrm{n}=8$ rats in each group. ROS, reactive oxygen species; $\mathrm{SOD}$, superoxide dismutase; MnSOD, manganese superoxide dismutase; $\mathrm{Cu} / \mathrm{ZnSOD}$, copper-zinc superoxide dismutase; OVX, ovariectomized; E2, estradiol; ME, methoxyestradiol.

However, the potential mechanism of HPH is complicated and remains poorly defined. HIF-1 is an important transcriptional factor, which serves an essential role in the hypoxia response and is a 'molecular switch', regulating target gene expression and affecting hypoxia-induced vascular remodeling $(18,19)$. HIF-1 is a heterodimeric transcription factor composed of a regulatory $\alpha$ subunit (HIF-1 $\alpha$ ) and a constitutive $\beta$ subunit (HIF-1 1 ) (20). HIF-1 $\alpha$ is a functional subunit that regulates the expression of $>100$ types of target genes involved in hypoxic stress and thus serves a crucial role in the response to hypoxia (21). The expression and activity of HIF-1 $\alpha$ are regulated mainly by cellular oxygen concentration (21); however, it is difficult to change a patient's anoxia status. A previous study demonstrated that factors other than hypoxia may enhance HIF-1 $\alpha$ mRNA expression, as the HIF-1 level did not increase in direct correlation to oxygen concentration (22). Accumulating evidence suggests that oxidative stress is involved in the regulation of HIF-1 expression and activity (23-27).

Oxidative stress (OS) is an imbalance between the production of ROS, which includes superoxide anion free radicals, hydrogen peroxide and hydroxyl radicals and the antioxidant capacity of the body (28). SOD provides a cellular defense mechanism by scavenging ROS, which constitutes one of the major defense mechanisms of cells against OS (29). In pathological conditions, such as hypoxia, excessive ROS interact with cellular proteins, lipids and DNA, resulting in oxidative cell and tissue damage, and/or behave as second messengers, promoting pulmonary vascular remodeling (30). Mitochondria are a key site of ROS production, but also represent a target for ROS and are compromised by severe or prolonged oxidative stress; this creates a vicious cycle to amplify mitochondrial ROS, which leads to subsequent mitochondrial dysfunction and oxidant generation (31). Accumulating evidence suggests that ROS serve an important role in HIF-1 $\alpha$ regulation; hypoxic exposure may increase ROS, and ROS, behaving as signaling molecules, activate HIF- $1 \alpha$, inhibit voltage-gated potassium channel expression and increase cytosolic calcium concentration, thereby leading to smooth 


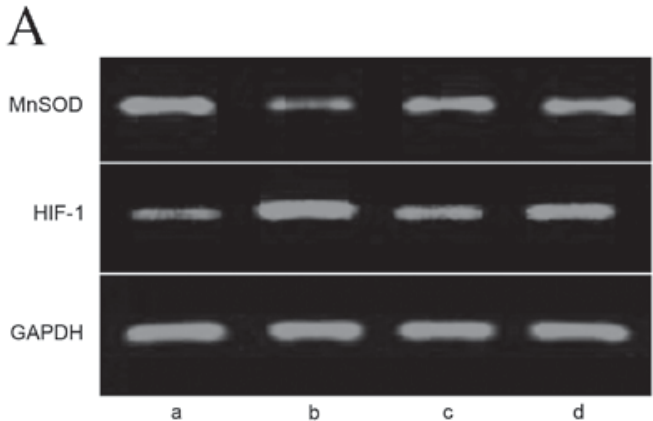

\section{B}
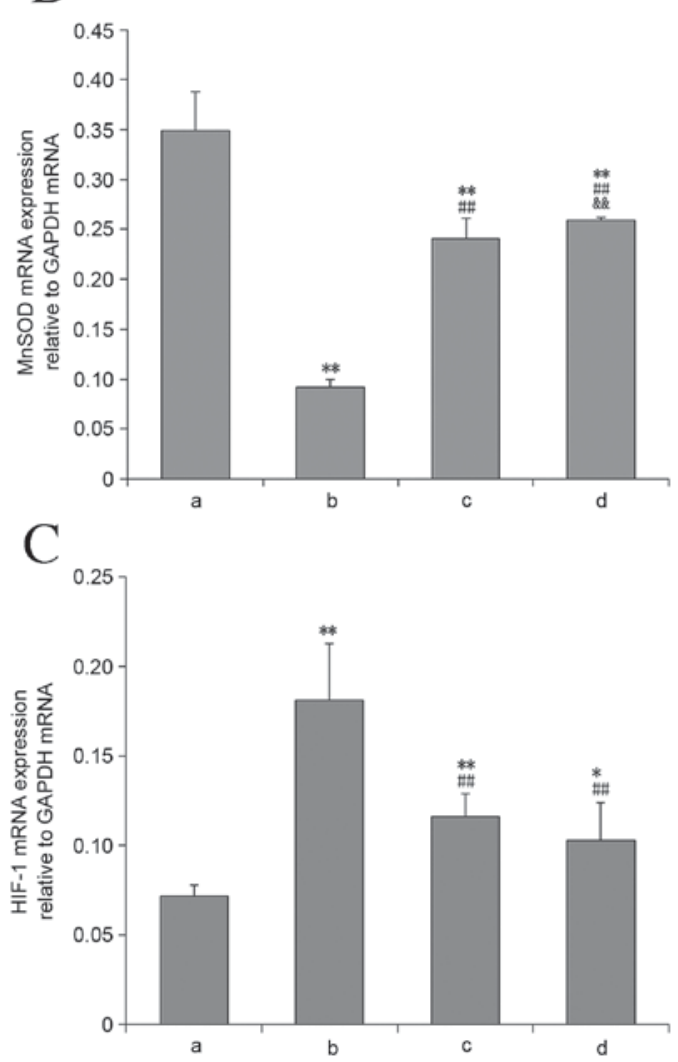

Figure 5. mRNA levels of (A and B) MnSOD and (A and C) HIF-1 $\alpha$ in lung tissues among the groups. (a) Control group; (b) OVX + hypoxia group; (c) OVX + hypoxia + E2 group; (d) OVX + hypoxia + 2ME group. " $\mathrm{P}<0.01$ and ${ }^{* *} \mathrm{P}<0.05$ vs. $\mathrm{a} ;{ }^{\# \#} \mathrm{P}<0.01$ vs. $\mathrm{b}$; and ${ }^{\& \&} \mathrm{P}<0.01$ vs. $\mathrm{c} . \mathrm{n}=8$ rats for each group. MnSOD, manganese superoxide dismutase; HIF-1 $\alpha$, hypoxia-inducible factor-1 $\alpha$; OVX, ovariectomized; E2, estradiol; ME, methoxyestradiol.

muscle contraction (23). Previous research demonstrated that augmenting SOD2-increased hydrogen peroxide-mediated redox signaling inhibited HIF-1 $\alpha$ activity and reduced pulmonary artery smooth muscle cell proliferation (24). Recent studies have reported that oxidative stress regulates the expression of HIF-1 $\alpha$ at both the protein and mRNA levels (25-27). A study on arsenic-induced carcinogenesis demonstrated that arsenic-induced ROS increases HIF-1 $\alpha$ transcription via inhibition of miR-199a expression (25). Sasabe et al (26) revealed that intracellular ROS, produced following the knockdown of Mn-SOD, enhanced HIF-1 $\alpha$ expression in oral squamous cell carcinoma cells through transcriptional, translational and posttranslational regulation under normoxic and hypoxic conditions. Fijalkowska et al (27) demonstrated that decreased expression of mitochondrial MnSOD, which influences

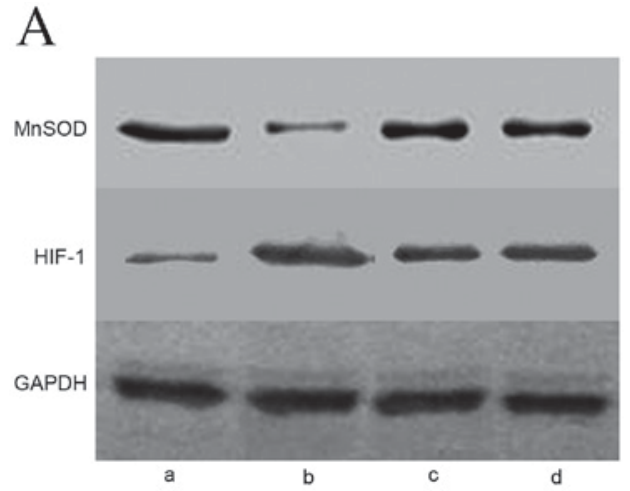

$\mathrm{B}$
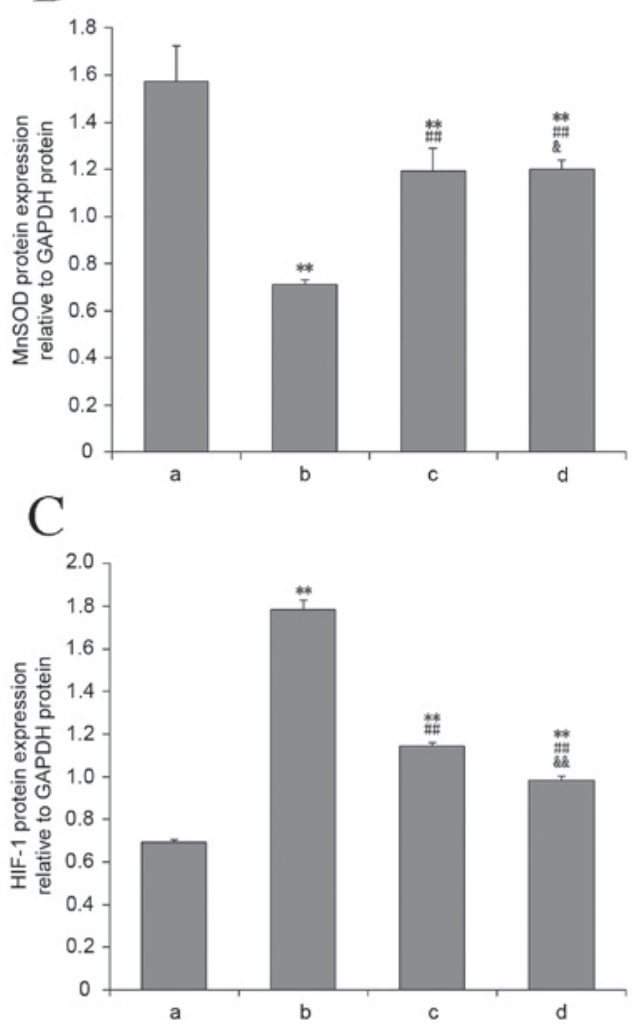

Figure 6. Protein levels of (A and B) MnSOD and (A and C) HIF-1 $\alpha$ in lung tissues among the groups. (a) Control group; (b) OVX + hypoxia group; (c) OVX + hypoxia + E2 group; (d) OVX + hypoxia + 2ME group. ${ }^{* *} \mathrm{P}<0.05$ vs. a; ${ }^{\# \#} \mathrm{P}<0.01$ vs. $\mathrm{b}$; and ${ }^{\&} \mathrm{P}<0.05$; ${ }^{\&} \mathrm{P}<0.01$ vs. c. $\mathrm{n}=8$ rats for each group. MnSOD, manganese superoxide dismutase; HIF-1 $\alpha$, hypoxia-inducible factor-1 $\alpha$; OVX, ovariectomized; E2, estradiol; ME, methoxyestradiol.

mitochondrial ROS levels and/or NO bioavailability, may be mechanistically implicated in the enhanced HIF-1 $\alpha$ expression in cultured endothelial cells from patients with idiopathic pulmonary arterial hypertension. A previous study indicated that oxidative stress and tissue hypoxia may serve as triggering signals for HIF-1 $\alpha$ activity and expression in irradiated lungs, leading to radiation-induced inflammation, angiogenesis and fibrosis (32).

In the present study, female rats were used and a model of HPH was successfully established by treatment with bilateral OVX and 8 weeks of hypoxia. Rats in group B had significantly increased mPAP, thickened pulmonary arteriolar walls and an increased number of smooth muscle cells, in which mitochondrial swelling, and crista fragmentation and disappearance were observed. Compared with the control group, 
serum ROS levels increased significantly, SOD and MnSOD levels markedly decreased, lung tissue MnSOD mRNA and protein expression decreased and HIF-1 $\alpha$ mRNA and protein expression were significantly increased in the model group. These results suggest that oxidative stress may contribute to the occurrence and development of HPH through the upregulation of HIF-1 $\alpha$ transcription and translation.

Previous studies have focused on the protective effects of E2 on the pulmonary vasculature, but the mechanisms behind these are unknown. Miyamoto et al (33) reported that E2 reduced the HIF-1 $\alpha$ mRNA level under hypoxic conditions. Determining whether E2 inhibits the expression of HIF-1 $\alpha$ by regulating oxidative stress will help to further the understanding of the mechanism of action of E2 in HPH. Wang et al (34) previously revealed that E2 protects against light-induced retinal damage via its antioxidative effect, and the etiology of this involves the upregulation of the gene expression levels of SOD. Liu et al (35) suggested that E2 upregulates SOD2 expression, resulting in reduced ROS generation, which largely favors cardiovascular function. In the present study, administration of E2 significantly ameliorated mitochondrial ultrastructural damage, and alleviated oxidative stress, as indicated by a significant decrease in the ROS level in serum, a significant increase in SOD and MnSOD levels in serum and a significant increase in MnSOD mRNA and protein expression in lung tissues. E2 therapy also significantly reduced tissue HIF-1 $\alpha$ mRNA and protein expression. The improvement in the aforementioned parameters was correlated with the observed amelioration of histological changes of pulmonary arteries. Hence, the protective effects of E2 on HPH may be mediated by its ability to decrease HIF-1 $\alpha$ mRNA and protein expression through its antioxidant potential.

$2 \mathrm{ME}$, an estrogen derivative, was recently reported to have antitumor and anti-angiogenesis functions. Recently, $2 \mathrm{ME}$ has been reported to downregulate HIF-1 $\alpha$ and inhibit the expression of its downstream target genes in tumor cells (36). However, the exact mechanism of the inhibition of HIF-1 $\alpha$ by $2 \mathrm{ME}$ is remains unclear, which may be due to a promoting effect on HIF-1 $\alpha$ protein degradation (36), an inhibitory effect on the translation and nuclear translocation of HIF-1 $\alpha$ protein (37), or a promoting effect on microtubule disruption (38). Previous research indicated that $2 \mathrm{ME}$ inhibits ROS generation whilst enhancing SOD activity, which may be responsible for its anti-angiogenic effect (39). The present study demonstrated that $2 \mathrm{ME}$ intervention significantly ameliorated mitochondrial ultrastructural injury, decreased the serum ROS level, increased serum SOD and MnSOD activities, increased MnSOD mRNA and protein expression in lung tissues, significantly reduced tissue HIF- $1 \alpha$ mRNA and protein expression and reduced mPAP and attenuated pulmonary vascular remodeling. These results suggest that 2ME may also inhibit HPH development by relieving oxidative stress and thereby downregulating HIF- $1 \alpha$ mRNA and protein expression.

In conclusion, the present report suggests that E2 and 2ME administration attenuates hemodynamic and remodeling parameters in ovariectomized female HPH rats, and suggests that the protective effects of E2/2ME may, in part, be mediated by the OS-HIF-1 pathway; however, the detailed mechanism of this requires additional study.

\section{Acknowledgements}

The present study was supported by the government Funding Program for Provincial Clinical Medical Talents.

\section{References}

1. Hoeper MM, Humbert M, Souza R, Idrees M, Kawut SM, Sliwa-Hahnle K, Jing ZC and Gibbs JS: A global view of pulmonary hypertension. Lancet Respir Med 4: 306-322, 2016.

2. Mandras SA, Gilkin RJ Jr, Pruett JA and Raspa S: Pulmonary arterial hypertension: Progress and challenges in the modern treatment era. Am J Manag Care 20 (Suppl 9): S191-S199, 2014.

3. Weir-McCall JR, Struthers AD, Lipworth BJ and Houston JG: The role of pulmonary arterial stiffness in COPD. Respir Med 109: 1381-1390, 2015.

4. Waypa GB, Marks JD, Guzy R, Mungai PT, Schriewer J, Dokic D and Schumacker PT: Hypoxia triggers subcellular compartmental redox signaling in vascular smooth muscle cells. Circ Res 106: 526-535, 2010.

5. Schumacker PT: Lung cell hypoxia: Role of mitochondrial reactive oxygen species signaling in triggering responses. Proc Am Thorac Soc 8: 477-484, 2011.

6. Sylvester JT, Shimoda LA, Aaronson PI and Ward JP: Hypoxic pulmonary vasoconstriction. Physiol Rev 92: 367-520, 2012.

7. Al Ghouleh I, Khoo NK, Knaus UG, Griendling KK, Touyz RM, Thannickal VJ, Barchowsky A, Nauseef WM, Kelley EE, Bauer PM, et al: Oxidases and peroxidases in cardiovascular and lung disease: New concepts in reactive oxygen species signaling. Free Radic Biol Med 51: 1271-1288, 2011.

8. Vara D and Pula G: Reactive oxygen species: Physiological roles in the regulation of vascular cells. Curr Mol Med 14: 1103-1125, 2014.

9. Wang L, Zhou Y, Li M and Zhu Y: Expression of hypoxia-inducible factor-1 $\alpha$, endothelin-1 and adrenomedullin in newborn rats with hypoxia-induced pulmonary hypertension. Exp Ther Med 8: 335-339, 2014.

10. Han X, Sun S, Zhao M, Cheng X, Chen G, Lin S, Guan Y and Yu X: Celastrol stimulates hypoxia-inducible factor-1 activity in tumor cells by initiating the ROS/Akt/p70S6K signaling pathway and enhancing hypoxia-inducible factor- $1 \alpha$ protein synthesis. PLoS One 9: e112470, 2014.

11. Frump AL, Goss KN, Vayl A, Albrecht M, Fisher A, Tursunova R, Fierst J, Whitson J, Cucci AR, Brown MB and Lahm T: Estradiol improves right ventricular function in rats with severe angioproliferative pulmonary hypertension: Effects of endogenous and exogenous sex hormones. Am J Physiol Lung Cell Mol Physiol 308: L873-L890, 2015.

12. Tofovic SP, Jones T and Petrusevska G: Dose-dependent therapeutic effects of 2-Methoxyestradiol on Monocrotaline-Induced pulmonary hypertension and vascular remodeling. Prilozi 31: 279-295, 2010.

13. Zheng Q, Yuan YD and Zhao J: Effect of estradiol and its metabolite on hypoxic induced factor-laand alkane hydroxylase in experimental rats with ovariectomy and hypoxic pulmonary hypertension. Chinese Circulation J 30: 884-888, 2015.

14. Yuan M, Duan Z, Sun Y and Yuan Y: Effects of estrogen on ACE-AngII-AT1 axis in ovariectomy and hypoxic pulmonary hypertension rats. Zhonghua Yi Xue Za Zhi 94: 1696-1700, 2014 (In Chinese)

15. Shen YX, Xiao K, Liang P, Ma YW and Huang X: Improvement on the modified Lowry method against interference of divalent cations in soluble protein measurement. Appl Microbiol Biotechnol 97: 4167-4178, 2013.

16. Simonneau G, Gatzoulis MA, Adatia I, Celermajer D, Denton C, Ghofrani A, Gomez Sanchez MA, Krishna Kumar R, Landzberg M, Machado RF, et al: Updated clinical classification of pulmonary hypertension. J Am Coll Cardiol 62 (Suppl 25): D34-D41, 2013.

17. Voelkel NF, Gomez-Arroyo J, Abbate A, Bogaard HJ and Nicolls MR: Pathobiology of pulmonary arterial hypertension and right ventricular failure. Eur Respir J 40: $1555-1565,2012$.

18. Prabhakar NR and Semenza GL: Adaptive and maladaptive cardiorespiratory responses to continuous and intermittent hypoxia mediated by hypoxia-inducible factors 1 and 2 . Physiol Rev 92: 967-1003, 2012. 
19. Abud EM, Maylor J, Undem C, Punjabi A,Zaiman AL, Myers AC, Sylvester JT, Semenza GL and Shimoda LA: Digoxin inhibits development of hypoxic pulmonary hypertension in mice. Proc Natl Acad Sci USA 109: 1239-1244, 2012.

20. Wang GL and Semenza GL: Purification and characterization of hypoxia-inducible factor 1. J Biol Chem 270: 1230-1237, 1995.

21. Semenza GL: Hypoxia-inducible factor 1: Regulator of mitochondrial metabolism and mediator of ischemic preconditioning. Biochim Biophys Acta 1813: 1263-1268, 2011.

22. Bruick RK and McKnight SL: A conserved family of prolyl-4-hydroxylases that modify HIF. Science 294: 1337-1340, 2001.

23. Archer SL, Marsboom G, Kim GH, Zhang HJ, Toth PT, Svensson EC, Dyck JR, Gomberg-Maitland M, Thébaud B, Husain AN, et al: Epigenetic attenuation of mitochondrial superoxide dismutase 2 in pulmonary arterial hypertension: A basis for excessive cell proliferation and a new therapeutic target. Circulation 121: 2661-2671, 2010.

24. Ahmed LA, Obaid AA, Zaki HF and Agha AM: Role of oxidative stress, inflammation, nitric oxide and transforming growth factor-beta in the protective effect of diosgenin in monocrotaline-induced pulmonary hypertension in rats. Eur J Pharmacol 740: 379-387, 2014

25. He J, Wang M, Jiang Y, Chen Q, Xu S, Xu Q, Jiang BH and Liu LZ: Chronic arsenic exposure and angiogenesis in human bronchial epithelial cells via the ROS/miR-199a-5p/HIF-1 $\alpha / \mathrm{COX}-2$ pathway. Environ Health Perspect 122: 255-261, 2014.

26. Sasabe E, Yang Z, Ohno S and Yamamoto T: Reactive oxygen species produced by the knockdown of manganese-superoxide dismutase up-regulate hypoxia-inducible factor-1alpha expression in oral squamous cell carcinoma cells. Free Radic Biol Med 48: 1321-1329, 2010.

27. Fijalkowska I, Xu W, Comhair SA, Janocha AJ, Mavrakis LA, Krishnamachary B, Zhen L, Mao T, Richter A, Erzurum SC and Tuder RM: Hypoxia inducible-factorlalpha regulates the metabolic shift of pulmonary hypertensive endothelial cells. Am J Pathol 176: 1130-1138, 2010.

28. Duracková Z: Some current insights into oxidative stress. Physiol Res 59: 459-469, 2010.

29. Li SY, Fu ZJ and Lo AC: Hypoxia-induced oxidative stress in ischemic retinopathy. Oxid Med Cell Longev 2012: 426769, 2012.
30. Aggarwal S, Gross CM, Sharma S, Fineman JR and Black SM: Reactive oxygen species in pulmonary vascular remodeling. Compr Physiol 3: 1011-1034, 2013.

31. Fukai T and Ushio-Fukai M: Superoxide dismutases: Role in redox signaling, vascular function, and diseases. Antioxid Redox Signal 15: 1583-1606, 2011.

32. Rabbani ZN, Mi J, Zhang Y, Delong M, Jackson IL, Fleckenstein K, Salahuddin FK, Zhang X, Clary B, Anscher MS and Vujaskovic Z: Hypoxia inducible factor 1alpha signaling in fractionated radiation-induced lung injury: Role of oxidative stress and tissue hypoxia. Radiat Res 173: 165-174, 2010.

33. Miyamoto N, Mandai M, Takagi H, Suzuma I, Suzuma K, Koyama S, Otani A, Oh $\mathrm{H}$ and Honda Y: Contrasting effect of estrogen on VEGF induction under different oxygen status and its role in murine ROP. Invest Ophthalmol Vis Sci 43: 2007-2014, 2002.

34. Wang S, Wang B, Feng Y, Mo M,Du F,Li Hand Yu X: 17 $\beta$-estradiol ameliorates light-induced retinal damage in Sprague-Dawley rats by reducing oxidative stress. J Mol Neurosci 55: 141-151, 2015.

35. Liu Z, Gou Y, Zhang H, Zuo H, Zhang H, Liu Z and Yao D Estradiol improves cardiovascular function through up-regulation of SOD2 on vascular wall. Redox Biol 3: 88-99, 2014.

36. Hagen T, D'Amico G, Quintero M, Palacios-Callender M, Hollis V, Lam F and Moncada S: Inhibition of mitochondrial respiration by the anticancer agent 2-methoxyestradiol. Biochem Biophys Res Commun 322: 923-929, 2004.

37. Ma L, Li G, Zhu H, Dong X, Zhao D, Jiang X, Li J, Qiao H, $\mathrm{Ni}$ S and Sun X: 2-Methoxyestradiol synergizes with sorafenib to suppress hepatocellular carcinoma by simultaneously dysregulating hypoxia-inducible factor-1 and -2. Cancer Lett 355: 96-105, 2014.

38. Verenich S and Gerk PM: Therapeutic promises of 2-methoxyestradiol and its drug disposition challenges. Mol Pharm 7: 2030-2039, 2010.

39. Basini G, Santini SE and Grasselli F: 2-Methoxyestradiol inhibits superoxide anion generation while it enhances superoxide dismutase activity in swine granulosa cells. Ann N Y Acad Sci 1091: 34-40, 2006. 